\title{
“Não sei estudar parada": inclusão escolar e nomadismo
}

"I do not know how to study stopped": school inclusion and nomadism

"No sé estudiar parada": inclusión escolar y nomadismo

\section{Betina Hillesheim}

Universidade de Santa Cruz do Sul, Santa Cruz do Sul, RS, Brasil

\section{Lílian Rodrigues da Cruz}

Universidade de Santa Cruz do Sul, Santa Cruz do Sul, RS, Brasil

\section{Resumo}

Este artigo discute algumas questões relacionadas ao nomadismo, articulando-as com a educação, a partir de uma pesquisa com crianças filhas de trabalhadores de circos ou parques de diversões. Entendendo o nomadismo como um movimento que subverte a identidade, isto é, os nômades como aqueles que introduzem a diferença, pode-se dizer que as crianças nômades misturam as identidades, contaminando-as em sua pretensa pureza: ao carregarem traços de vários lugares, embaralham as fronteiras já estabelecidas. Deste modo, ao voltar-se para a inclusão escolar dos nômades, o texto propõe pensar a diferença não como diversidade, mas multiplicidade, experimentando novas conexões para a educação escolar.

Palavras-chave: Nomadismo, Identidade e Diferença, Educação.

\section{Resumen}

Este artículo discute algunas cuestiones pertinentes al nomadismo, articulándolas con la educación, a partir de una pesquisa con niños hijos de trabajadores de circos o de parques de diversiones. Entendiendo el nomadismo como un movimiento que subvierte la identidad, o sea, los nómades como aquellos que introducen la diferencia, se puede decir que los niños nómades mezclan las identidades, contaminándolas en su pretensa pureza: al cargamento están rasgos de varios lugares, abarajando las fronteras ya establecidas. Así, al volverse para la inclusión escolar de los nómades, el texto que sigue propone pensar la diferencia no como adversidad, sino como multiplicidad, experimentando nuevas conexiones para la educación escolar. 
Palabras clave: Nomadismo, Identidad y Diferencia, Educación.

\begin{abstract}
This article discusses some questions related to the nomadic life, linking them with education, from a research with children of circus workers circus or amusement parks. Understanding the nomadism as a movement that subverts the identity, that is, the nomads as those that introduce the difference, we can say that nomad children mix identities, contaminating in their alleged purity: loading traces of several places, shuffling the borders already established. In this way, by turning to educational inclusion of the nomads, the text proposes to think the difference not as a diversity, but multiplicity, experiencing new connections to the school education.
\end{abstract}

Keywords: Nomadism, Identity and Difference, Education.

Era uma vez, mas eu me lembro como se fosse agora. Eu queria ser trapezista, minha paixão era o trapézio. Me atirava do alto na certeza que alguém seguravame as mãos não me deixando cair.

Era lindo, mas eu morria de medo, tinha medo de tudo quase: cinema, parque de diversão, de circo, ciganos, aquela gente encantada que chegava e seguia. Era disso que eu tinha medo. Do que não ficava pra sempre.

Era outra vez outro parque, outro circo, ciganos e patinadores. O circo chegou à cidade, era uma tarde de sonhos e eu corri até lá. Os artistas se preparavam nos bastidores para começar o espetáculo e eu entrei no meio deles e falei que queria ser trapezista. [...]

De repente apareceu uma luz lá no alto e todo mundo ficou olhando, a lona do circo tinha sumido e o que eu via era a estrela Dalva no céu aberto. Quando eu cansei de ficar olhando pro alto e fui olhar pras pessoas, só aí eu vi que estava sozinha.
(Texto de Antônio Bivar, extraído do disco Drama, $3^{\circ}$ ato, 1973, de Maria Bethânia)

Os circos e parques de diversões mobilizam afetos diversos, oscilando entre atração e medo. Filmes, como o recente Água para Elefantes (2011, direção de Francis Lawrence), mostram os efeitos de suas passagens pelas cidades, encantando adultos e crianças. Da noite para o dia, terrenos baldios transformam-se em terras repletas de tendas, gente, cores, cheiros, euforia. Por outro lado, a provisoriedade causa desconforto: quem são esses que não se fixam em lugar algum?

Neste artigo $^{1}$ buscamos discutir algumas questões relacionadas ao nomadismo, articulando-as com a educação, a partir de uma pesquisa ${ }^{2}$ com crianças filhas de trabalhadores de circos ou parques de diversões. Se entendermos o 
nomadismo como um movimento que subverte a identidade, isto é, os nômades como aqueles que introduzem a diferença, podemos indagar: como as crianças nômades desestabilizam as identidades de aluno ou professor? Afinal, os nômades misturam as identidades, contaminando-as em sua pretensa pureza: ao carregarem traços de vários lugares, as crianças nômades embaralham as fronteiras já estabelecidas.

Antes de seguir, cabe indagar: o que são nômades? Porém, não se trata de responder à questão, mas, a partir do deslocamento desta, fornecer alguns indícios, alguns sinais, mediante contrastes ou aproximações, para, mesmo que parcialmente ou, às vezes, sem muita nitidez, pensar algumas questões relativas à infância, a partir da ideia de nomadismo. Como colocam Wortmann e Veiga-Neto (2001), questões marcadas pelo o que é isso indicam uma falta de clareza ou um incômodo sobre isso, visto que, na medida em que há uma insuficiência do conceito, não podem ser respondidas. $O$ equívoco está na própria noção de conceito, pois este não pode ser reduzido a uma proposição. Portanto, quando nos propomos a pensar o que são nômades, não pretendemos capturar este conceito a partir de uma definição, mas, ao modo deleuziano, sair dela.
Uma primeira aproximação, entre tantas outras possibilidades, é buscar o sentido etimológico do termo. Com isto, não estamos afirmando uma suposta origem do conceito que remeta a uma essência primeira, mas, simplesmente, buscamos algumas pistas que nos auxiliem a combinar alguns conceitos sobre $\mathrm{o}$ nomadismo. A partir desta entrada, constatamos que a palavra nômade originase do latim - nomas -, estando associada a um povo errante pastoral. O termo foi emprestado do grego - nomás -, significando errante, aquele que vaga em busca de novas pastagens para o rebanho.

Se recorrermos aos dicionários, encontramos os seguintes níveis de significados $^{3}$ : 1) tribos e raças humanas que não têm sede fixa e vagueiam errantes e sem cultura, 2) o que não tem residência fixa, vagabundo e cuja atividade é desconhecida, 3) povos pastores sem domicílio fixo, 4) aquele que leva um gênero de vida não sedentária.

Neste ponto, um primeiro deslocamento: ao invés de perguntar o que são nômades, podemos indagar quem são eles. Errantes, sem residência fixa: grupos pastoris, ciganos, tribos indígenas, trabalhadores de circo e parques de diversões, entre outros. Aos nômades, são associados atributos negativos: vagabundos que deixam rastros de destruição e abandono por onde passam. A partir disto, 
evidenciamos que os nômades são estranhos, forasteiros, ameaçadores, desconhecidos, perigosos... Não se fixam, dificultam nossa compreensão, não se enquadram nas normas sedentárias. Como trata Silva (2002), os diferentes não pedem tolerância, respeito ou boa vontade, mas, desrespeitosamente, simplesmente diferem.

Assim, temos inúmeros exemplos de discriminação e rechaço aos grupos nômades, sendo que um dos mais recentes é o caso da expulsão dos ciganos romenos da França, relacionando-se nomadismo e criminalidade. Neste sentido, é significativa a fala do porta-voz do Ministério dos Negócios Estrangeiros francês, Bernard Valero, ao lembrar que a Comissão Européia deve 'apoiar os programas de reintegração' dos ciganos em seus países de origem e enfatizando a existência de uma diretriz da União Européia que permite a restrição da livre circulação por razões de ordem, segurança ou saúde pública ${ }^{4}$. Podemos assinalar ainda o extermínio dos ciganos pelo regime nazista, fato geralmente pouco lembrado. $\mathrm{Ou}$ situações como relatadas pela pesquisadora Verônica Tamaoki ${ }^{4}$, envolvendo acusações a trabalhadores de circo em casos de desaparecimento de crianças ou cães nas cidades nas quais esses se apresentavam.

Um novo deslocamento: o nomadismo não só como um modo de vida de alguns grupos sociais, mas também como um conceito que pode nos auxiliar a problematizar algumas questões. Deleuze e Guattari (1997), ao discorrerem sobre o nomadismo, salientam que o nômade possui um território, seguindo trajetos costumeiros que vão de um ponto a outro. Porém, embora os pontos determinem os trajetos, um trajeto está sempre entre dois pontos, sendo que o ponto somente existe como alternância. "A vida do nômade é intermezzo" (p. 51). Deste modo, são criados espaços, passagens, a partir dos quais o nômade vai de um ponto a outro, deixando rastros. O nômade reinventa as fronteiras e determina os trajetos.

A partir disto, quais aproximações são possíveis entre os nômades e a escola? $\mathrm{Na}$ medida em que a obrigatoriedade de escolarização atinge a todos, os nômades acabam também por ser incluídos, a partir de garantias legais de acesso e permanência à escola. A lei federal 6.533/78, Art. 29, estabelece que os filhos dos profissionais de que trata esta Lei, cuja atividade seja itinerante, terão assegurada a transferência da matrícula e conseqüente vaga nas escolas públicas locais de $1^{\circ}$ e $2^{\circ}$ Graus, e autorizada nas escolas particulares desses níveis, mediante apresentação de certificado da escola de origem (Brasil, 1978). Por sua vez, para a Constituição Federal de 1988, "a educação é direito de todos e dever do 
Estado" (artigo 205), sendo que o artigo 206, que trata sobre os princípios que regem o ensino, determina, em seu inciso I, "igualdade de condições para o acesso e permanência na escola". Além disto, o artigo 208 (inciso III) estabelece o direito de as pessoas com necessidades especiais receberem educação preferencialmente na rede regular de ensino (Brasil, 1988). Portanto, discutimos, a seguir, alguns dos efeitos deste encontro entre os nômades e a escola, entendendo-a como uma instituição que se insere nos modos de vida sedentários.

\section{Escola e Nômades: (Des)encontros}

As crianças de circo ou parque de diversões têm uma rápida passagem pelas cidades, especialmente no primeiro caso, pois os circos permanecem em torno de duas semanas em cada lugar. A lei lhes garante a matrícula nas escolas. Ao final do ano, necessitam ser avaliadas. Nômades, mas sujeitas a normas: há regras para transitar, mas também para se fixar (locais determinados, exigências a cumprir, autorizações, taxas, alvarás, matrículas, transferências). Entre as escolas, transitam as crianças e também papéis, notas, conteúdos.

Ao mesmo tempo, há poucos registros destas passagens pelas escolas. Fugazes, vão e vêm, parecendo escapar às tentativas de captura: os professores questionam sobre suas aprendizagens, queixam-se de não ter dados suficientes para avaliação, reclamam das condutas. Crianças artistas, distraem os outros alunos com seus malabarismos, acrobacias, truques de mágicas, ofertas de visitas ao circo ou ao parque, ou, simplesmente, histórias. A escola se transforma, por um rápido instante, em um picadeiro circense: as outras crianças se dispersam, agitam-se, pais reclamam, essas crianças atrapalham a concentração da turma.

Quase invisíveis, ao se defrontarem com os espaços escolares, ganham, por alguns momentos, contornos nítidos. Porém, logo desaparecem nas sombras da vida nômade: mudam-se, despedem-se, talvez retornem em outro ano, talvez não. Embora numerosos, quase não são vistos ou falados; a escola pouco modifica sua rotina, os conteúdos são os mesmos, as avaliações seguem seu ritmo. Ficam alguns incômodos: será que aprendem? O que aprendem? Como aprendem?

Os nômades são avaliados a partir do parâmetro de uma vida sedentária: uma pesquisa desenvolvida por Xavier e Santos (2009), com crianças circenses, aponta situações diversas de discriminação. De acordo com esse estudo, essas crianças, muitas vezes, não recebem os livros didáticos ou uniformes escolares, sob a alegação que não costumam devolvê-los. 
Assinalam, ainda, a existência, no ambiente escolar, de uma noção de que essas crianças não têm condições de aprender, sendo-lhes reservado um lugar de ouvintes, sem um compromisso maior da escola com sua aprendizagem. Outro aspecto refere-se à repetição ou lacuna de determinados conteúdos, visto que há pouca preocupação em conhecer o que já foi visto por esses alunos nas outras escolas.

Há, assim, uma constante tensão entre estilos de vida nômade e sedentário. A escola, a partir de uma lógica disciplinar, delimita tempos e espaços, podendo ser entendida apenas como um ponto. Para os nômades, o que importa não são os pontos, mas o trajeto. Para Deleuze e Guattari (1997), é preciso distinguir o que é princípio e o que é somente consequência da vida nômade: para estes, "ainda que os pontos determinem trajetos, estão estritamente subordinados aos trajetos que eles determinam, ao contrário do que sucede no caso do sedentário" (p. 50). Diferente do migrante, que passa de um ponto a outro com a intenção de fixidez, para o nômade os pontos apenas constituem-se como alternância do trajeto. No caso das crianças de circos ou parques de diversões, as escolas só adquirem sentido na medida em que se configuram como pontos do trajeto percorrido: os elementos de seu habitat (os locais de acampamento, os serviços de saúde, as escolas...) são concebidos a partir de um trajeto que está sempre a se modificar.

A escola preocupa-se com os pontos de chegada e partida, sendo que os instrumentos de avaliação buscam medir a distância entre um e outro. Uma das questões que surgiram no contato com escolas, traz a avaliação dessas crianças como um problema: se à última escola do período letivo cabe avaliar, como fazê-lo? Há pouco interesse pelo meio: o que acontece no processo escolar destas crianças? Entretanto, no caso do nomadismo, como assinalam Deleuze e Parnet (1998), não se trata de início ou de fim. O interessante é o que se passa entre, o trajeto, e não os pontos. Deleuze (2006) diz que, em nossos regimes, os nômades são infelizes, visto que têm dificuldade de viver diante das constantes tentativas de fixá-los. As escolas aceitam a matrícula dessas crianças, por força de lei, mas a todo instante lamentam sua não submissão às regras sedentárias. Oportuno apontar que uma das falas de professores, ao comparar crianças de circo e parques de diversões, aponta como vantajoso o fato dessas últimas, em geral, terem um maior tempo de permanência na mesma escola.

Além disto, enquanto a escola busca a distribuição das pessoas em um espaço fechado, o trajeto nômade realiza uma distribuição dos homens de um modo 
muito especial, num espaço aberto, indefinido, não cercado. Há, portanto, como pontuam Deleuze e Guattari (1997), uma grande diferença de espaço: enquanto o espaço sedentário (que aqui identificamos como a escola) é um espaço estriado, ou seja, marcado por muros, fronteiras, caminhos pré-determinados, o espaço nômade é liso, caracterizando-se somente por traços que se apagam ainda no trajeto.

Porém, conforme esses autores, embora às vezes possamos realizar uma oposição simples entre os espaços liso e estriado, noutras indica-se uma diferença muito mais complexa: devemos lembrar que os dois espaços só existem misturados. “O espaço liso não pára de ser traduzido, transvertido num espaço estriado; o espaço estriado é constantemente revertido, devolvido a um espaço liso" (Ibidem, p. 180). Pontuam também que o Estado tem como uma de suas principais tarefas estriar o espaço ou então utilizar os espaços lisos como formas de comunicação que servem a um espaço estriado. Para o Estado, é fundamental superar o nomadismo e capturar os fluxos, determinando trajetos e direções, regulando a velocidade e limitando o movimento.

As crianças nômades modificam a velocidade da escola, produzindo aceleração, condensando o ano escolar em poucos dias ou semanas. Os nômades, apesar dos esforços de apreensão, nunca estão onde se espera, imprimindo velocidade absoluta aos movimentos, sempre em busca de novas paisagens. Escapam aos controles, às contagens, às regulações, funcionando como máquinas de guerra que implodem a disciplina escolar. Para Deleuze (1992), uma 'máquina de guerra' não se define pela guerra, mas por um modo de ocupar o espaço-tempo ou inventar novos espaçostempos. Desta maneira, podemos pensar os nômades como aqueles que buscam liberar a vida, traçando linhas de fuga, respondendo ao intolerável.

Uma das meninas entrevistadas diz: não sei estudar parada. A escola, por sua vez, busca a fixidez dos corpos, constituindo-se como um espaço privilegiado no qual se põe em jogo o governo da infância. Nesta perspectiva, em sua análise sobre a Didática Magna, de Comenius, Corazza (2002) aponta que a Pedagogia se constitui como “o domínio em que a arte de governar os infantis e suas vidas se produzirá" (p.157). Porém, os nômades resistem, pois, mesmo estando na escola, deixam poucos rastros: algumas lembranças, poucos vínculos. A escola pouco modifica seu funcionamento, sendo que cabe aos nômades adequarem-se. Maleáveis, misturam-se aos outros alunos, fazendo trabalhos e frequentando as aulas. Ao levantar acampamento, levam na 
bagagem as necessárias notas pra apresentar na escola seguinte. Não estudar parado implica problematizar as formas pelas quais, frequentemente, se entende tanto o aprender como a avaliação escolar. Quais os efeitos deste (des)encontro?

\section{Da Diversidade à Multiplicidade:}

\section{Alguns Apontamentos}

Desde o final do século $\mathrm{XX}$, dissemina-se o discurso da inclusão, sendo que, paulatinamente, determinadas parcelas da população são nomeadas como objetos desse discurso: os deficientes, os loucos, os criminosos, os negros, os índios, as mulheres, os nômades... Para dar conta das necessidades destes grupos, são criadas políticas públicas e ações específicas. Desta maneira, Gallo (2009) pontua que o tema da diversidade na educação tornou-se presente nas pesquisas educacionais, nas práticas pedagógicas, nas políticas de educação. A atenção à diversidade é defendida na busca de uma universalização do aceso à escola; portanto, "a escola é afirmada como o lugar das diferenças, o lugar do respeito às diferenças" (s/p.). Esta noção de diversidade é afirmada a partir da identidade e da universalidade, sendo o diferente pensado como aquele que não é idêntico e a universalidade como o conjunto das diversas identidades. Contudo, pensar a diversidade a partir da identidade e da universalidade é um simulacro, ou seja, trata-se de uma falsa diversidade, a qual encerra a diferença no próprio conceito de diferença, sendo o diferente tomado sempre em relação ao idêntico.

Nesta perspectiva, trazemos as assertivas iniciais do texto Impertinências, de Silva (2002), fundamentado nas ideias da Filosofia da Diferença. Na primeira, afirma: "a diferença não tem nada a ver com o diferente. A redução da diferença ao diferente equivale a uma redução da diferença à identidade". Em seguida, assinala: "A multiplicidade não tem nada a ver com a variedade ou a diversidade. A multiplicidade é a capacidade que a diferença tem de (se) multiplicar" (p. 66).

Voltar-se para a inclusão escolar dos nômades é um exercício para pensar a diferença não como diversidade, mas multiplicidade, buscando compreender não a diferença entre um e outro modo de vida (sedentário e nômade), mas o que se passa entre um e outro. Desta maneira, se tomarmos os efeitos do encontro entre os nômades e a escola, podemos, ao invés de, colados à identidade, afirmar o que a escola é, experimentarmos outras formas, indagando o que fazer com a mesma: como seria uma escola nômade? Como diz Silva (2002), a questão não se reduz ao reconhecimento da multiplicidade, mas à busca de outras conexões. 
Para finalizar, gostaríamos de marcar que este é um texto nômade. Deste modo, é um texto que, indo de um ponto a outro, preocupa-se mais com a velocidade do que com os pontos. Mais do que reconhecer ou reproduzir, busca criar, sem a intenção de fixar um único sentido. Assim, quem sabe, possamos fazer $\mathrm{o}$ pensamento funcionar a partir de outras bases, deixando-nos afetar e introduzindo certo mal-estar, estabelecendo novas composições. Afinal, como lembram Tadeu, Corazza e Zordan (2004), pensar é uma aventura em um espaço aberto, liso, selvagem: pensar é perder-se no deserto. Esperamos que os(as) destinatários(as) deste texto tenham se perdido conosco, pois um deserto é necessariamente povoado e o pensar somente se faz em bando, a partir de encontros.

\section{Notas}

1 Uma primeira versão deste texto foi apresentada no XIII Encontro Regional Sul da ABRAPSO, 2010, Maringá/PR.

2 Trata-se de um estudo em andamento, intitulado 'Infância, educação e nomadismo', realizado junto a escolas de Santa Cruz do Sul, Encantado e Santa Maria (RS). Participam ainda da pesquisa: Karen Cristina Cavagnoli (BIC/CNPq), Letícia Aline Back (PUIC/UNISC), Alexsander Witt Rodrigues
(PROBIC/FAPERGS), Gisele Santin (mestranda em Educação - UNISC, bolsista CAPES) e Letícia Lorenzoni Lasta (mestre em educação - UNISC, doutoranda em Psicologia Social e Institucional - UFRGS).

3 Significados retirados a partir de uma busca nos dicionários Michaelis (2009) e Aurélio (2010).

${ }^{4}$ Notícia veiculada na versão online de DN Globo, em 19 de agosto de 2010 (http://dn.sapo.pt/inicio/globo/interior.aspx ?content_id=1643938\&seccao=Europa)

5 Entrevista publicada em http://www.ubci.com.br/node/39 (acesso em 30 de setembro de 2010).

\section{Referências}

Brasil. Lei 6.533, de 24 de maio de 1978. Disponível em: http://www.planalto.gov.br/ccivil_03 /Leis/L6533.htm (acesso em 07 jan. 2010)

Brasil. (2001) Constituição da Republica Federativa do Brasil de 1988. 27 edição. São Paulo: Saraiva.

Corazza, Sandra Mara. (2002) Infância e educação. Era uma vez... quer que conte outra vez? Rio de Janeiro: Vozes.

Deleuze, Gilles; Guattari, Félix. (1997) Mil platôs. Capitalismo e esquizofrenia. v.5, São Paulo: Editora 34. 
Deleuze, Gilles; Parnet, Claire. (1998) Diálogos. São Paulo: Editora Escuta.

Deleuze, Gilles. (2006) Pensamento nômade. In Deleuze, Gilles. A ilha deserta. São Paulo: Iluminuras, p. 319-329.

Deleuze, Gilles. (1992) Conversações. Rio de Janeiro: Editora 34.

Gallo, Sílvio. (2009) Identidade, diversidade, universalidade e educação: experimentar minorações na língua e na educação. In: I Congresso Internacional de Filosofia da Educação de Países e Comunidades de Língua Portuguesa, São Paulo.

Silva, Tomaz Tadeu da. (2002) Identidade e diferença: impertinências. Educação \& Sociedade. Ano XXIII, n. 79, agosto, p. 65-66.

Tadeu, Tomaz; Corazza, Sandra; Zordan, Paula. (2004) Linhas de escrita. Belo Horizonte: Autêntica.

Wortmann, Maria Lúcia C. \& Veiga-Neto, Alfredo. (2001) Estudos Culturais da Ciência: que é isso? In Wortmann, Maria Lúcia C.; Veiga-Neto, Alfredo. Culturais da Ciência \& Educação. Belo Horizonte: Autêntica, p. 25-47.

Xavier, G. do C. \& Santos, A. A. de O. (2009) Exclusão escolar e a criança de circo. Revista Eletrônica de Educação. São Carlos, SP: UFSCar, v.3, $\mathrm{n}^{\circ} . \quad 2, \quad$ p. 118-129, nov. Disponível em http://www.reveduc.ufscar.br.

$\overline{\text { Betina Hillesheim. Psicóloga, doutora em }}$ Psicologia (PUCRS), docente e pesquisadora do departamento de Psicologia e do Mestrado em Educação na Universidade de Santa Cruz do Sul (UNISC).

E-mail:betinah@unisc.br

Lílian Rodrigues da Cruz. Psicóloga, doutora em Psicologia (PUCRS), docente e pesquisadora do departamento de Psicologia na Universidade de Santa Cruz do Sul (UNISC). Bolsista de Pósdoutorado Júnior do Conselho Nacional de Desenvolvimento Científico e Tecnológico (CNPq).

E-mail:liliancruz2@terra.com.br

Endereço para correspondência: Universidade de Santa Cruz do Sul. Av. Independência, 2293 Bloco 35 Departamento de Psicologia Bairro Universitário Santa Cruz do Sul (RS) BRASIL CEP: 96815-900. 